Between-person and within-person effects of telework: A quasi-field experiment

Joni Delanoeije ${ }^{\mathrm{a}, \mathrm{b} *}$ and Marijke Verbruggen ${ }^{\mathrm{a}, \mathrm{c}}$

${ }^{a}$ Work and Organisation Studies, Faculty of Economics and Business, KU Leuven, Belgium

${ }^{b}$ https://orcid.org/0000-0002-4372-9518

${ }^{c} \underline{\text { https://orcid.org/0000-0002-7375-7771 }}$

* Corresponding author: Work and Organisation Studies, Naamsestraat 69 - bus 3545, 3000

Leuven, e-mail: joni.delanoeije@ kuleuven.be, phone: +32 16329727 


\section{Between-person and within-person effects of telework: A quasi-field experiment}

This quasi-experimental study examines the impact of telework on employees' stress, work-tohome conflict, work engagement and job performance on a between-person and a within-person level. Data were collected in a Belgian company that had launched a pilot telework initiative. Employees in the intervention group $(\mathrm{N}=39)$ were allowed to work from home on at most two days a week whereas employees in the control group $(\mathrm{N}=39)$ were not. To examine changes in person-level outcomes over time, we collected data before telework was introduced (T1) and at the end of the pilot (T2). To examine day-level effects, we collected daily data on 13 consecutive workdays after the onset of the pilot. Multivariate repeated measures MANOVA showed no significant interaction effect between group and measurement occasion, yet univariate analyses showed that employees in the teleworking group had less stress at T2 compared to T1. No univariate differences in work-to-home conflict, work engagement or job performance were found over time. Daily analyses using linear mixed coefficient modeling showed that teleworkers reported lower stress, lower work-to-home conflict, higher work engagement and higher job performance on teleworking days compared to non-teleworking days.

Keywords: telework; intervention; daily diary; employee wellbeing; employee performance

Number of words: 12919

\section{Introduction}

Home-based telework - hereafter referred to as telework - is a work arrangement that allows employees to execute working tasks from home during some portion of the working week using information and communication technologies (Bailey \& Kurland, 2002). This work arrangement is gaining interest in modern organizations (Allen, Golden \& Shockley, 2015) since it allows organizations to decrease office costs (Bailey \& Kurland, 2002) and can help to maintain a healthy and well performing workforce (Standen, Daniels \& Lamond, 1999). In particular, as telework gives employees more resources-i.e., more flexibility and autonomy over the place and time of working (Allen, Renn \& Griffeth, 2003; Kossek, Lautsch \& Eaton, 
2006; Maruyama \& Tietze, 2012; Standen et al., 1999)— it is believed that telework can help to lower employees' stress (Kröll, Doebler, \& Nüesch, 2017; Thompson \& Prottas, 2006), decrease their work-home conflict (Allen, Golden, \& Shockley, 2015), enhance their work engagement (Ten Brummelhuis, Oerlemans, \& Bakker, 2016; Masuda, Holtschlag, \& Nicklin, 2017) and increase their job performance (Gajendran \& Harrison, 2007), among others.

However, research that examines the relationship between the use of telework and these outcomes remains inconclusive (Biron \& van Veldhoven, 2016; Boell, Cecez-Kecmanovic \& Campbell, 2016; Gajendran \& Harrisson, 2007). Whereas some studies and meta-analyses on the topic found that the use of telework is associated with the expected favorable outcomes (Allen et al., 2001; Casper et al., 2007; Gajendran \& Harrison, 2007; Golden, Veiga, \& Simsek, 2006; Harker Martin \& MacDonnell, 2012; Hill et al., 1998; Kossek et al., 2006), other studies and meta-analyses found null-effects (Kröll et al., 2017; Mesmer-Magnus \& Viswesvaran, 2006; Morganson et al., 2010) or even unfavorable outcomes, such as higher stress (Mann \& Holdsworth, 2003), more work-to-home conflict (Hammer et al., 2005), lower work engagement (Sardeshmukh, Sharma \& Golden, 2012), and lower job performance (Beauregard \& Henry, 2009).

One explanation for the fact that some studies have found null-effects and unfavorable outcomes of telework may lie in the implementation of telework, which sometimes undermines the most important benefit of telework, i.e., enhanced flexibility and autonomy (Kossek et al., 2006). For instance, when supervisors do not fully trust their employees who work from home, they may control them more, rather than less, for instance by monitoring their laptop activity (Groen et al., 2018). This could result in less-instead of moreperceived autonomy and therefore trigger unfavorable outcomes. Another explanation relates to potential negative side-effects that telework can bring along, most importantly the risk for boundary blurring (Delanoeije, Verbruggen \& Germeys, 2019). Since the home and the work 
role are co-located when people work from home (Gajendran \& Harrison, 2007; Schieman \& Young, 2010), boundaries get more blurred, which can create stress, increase work-to-home conflict and lower performance.

Besides these content-related explanations, several authors (Allen \& Eby, 2016; Biron \& van Veldhoven, 2016) have pointed to methodological explanations for the found inconsistencies in research on outcomes of telework. In particular, most research examining the impact of telework compares outcomes among users and non-users of telework—or among employees with different levels of teleworking intensity-using a cross-sectional or multiple-wave design (Allen \& Eby, 2016; Biron \& van Veldhoven, 2016; Gajendran \& Harrison, 2007). This approach has two main shortcomings.

First, this approach is not able to rule out selection effects, i.e., the influence of ex-ante differences between employees who use telework and those who do not use this practice. For instance, research has shown that in particular employees with the highest need for telework- e.g., employees who have high stress levels or who experience high work-home conflict (Allen et al., 2005; Bailey \& Kurland, 2000; Hammer et al., 2011)—use this practice. As such, when telework studies find similar or higher levels of stress or work-home conflict among users of telework compared to non-users, this finding could imply that telework is ineffective as a stress-reducing or work-home practice, but it could also be due to higher exante levels of stress or work-home conflict among the group of users. Several scholars have therefore urged for telework intervention studies (Allen et al., 2015; Antonakis, Bendahan, Jacquart \& Lalive, 2010; Brough \& O’Driscoll, 2010), preferably in a naturalistic setting (Nielsen \& Miraglia, 2017), as this study design enables researchers to control for potential selection effects that could alternatively explain observed effects. As such an intervention design can detect ex-ante differences between the intervention and the control group and, if present, control for them (Allen et al., 2015; Antonakis, Bendahan, Jacquart \& Lalive, 2010; 
Brough \& O’Driscoll, 2010), this design allows researchers to rule out selection effects as an alternative explanation for found effects (Cook, Campbell \& Shadish, 2002; Shadish \& Cook, 2009).

Second, the dominant approach to study the impact of telework focuses on discovering differences between users and non-users of telework. Although some effects of telework may indeed occur on a between-person level (e.g., teleworkers feel more trusted than nonteleworkers thanks to the enhanced autonomy, which they may want to reciprocate by increased engagement and performance), other effects may only emerge on days on which the teleworker worked from home and may therefore result in day-to-day (i.e., within-person) differences, but not necessarily in differences between users and non-users of telework (i.e., between-person effects). For instance, researchers have argued that teleworkers may experience less work-home conflict because they can do some home tasks during their working day, such as doing the laundry or picking up their children from school (Golden et al., 2006); however, this only applies to teleworking days. Similarly, it has been said that teleworkers may work more productively because they experience less interruptions from their colleagues (Windeler et al., 2017); however, reduced interruptions from colleagues are likely to be specific to teleworking days and could not be expected on office days. These arguments therefore suggest within-person differences (i.e., different outcomes on teleworking days compared to office days), which—as research in other domains has demonstrated (Dalal et al., 2000; Vancouver, Thompson \& Williams, 2001; Vega et al., 2015) — do not necessarily aggregate into between-person effects since other mechanisms may be at play. In order to understand the impact of telework, it is therefore important not only to look at differences between users and non-users of telework, but also to examine day-specific effects. 
This study aims to improve our understanding of the impact of telework by simultaneously examining between-person and within-person effects of telework using a quasi-experimental design. Although telework studies have started to examine day-level effects of telework (Anderson, Kaplan, \& Vega, 2014; Biron \& van Veldhoven, 2016; Delanoeije, Verbruggen \& Germeys, 2019; de Vries, Tummers, \& Bekkers, 2018; Vega, Anderson \& Kaplan, 2015), no study—to the best of our knowledge-has simultaneously examined both levels into one study. By simultaneously examining between-person and within-person effects in an intervention design, our study may help researchers and organizations to better understand how telework affects different employee outcomes (i.e., triggering general changes or rather affecting the daily job experiences dependent on the place of working; Vega et al., 2015) while simultaneously accounting for potential selection effects. In line with the dominant discourse on telework (Kossek et al., 2006), we will apply a resource perspective to telework, focusing on the favorable effects of enhanced flexibility, autonomy and control that telework-when implemented well—can bring along (Kossek et al., 2006). In what follows, we develop hypotheses for both between-person and a withinperson (i.e., day-to-day) effects of telework. We focus on four outcomes which have been regularly associated with telework on a between-person level and occasionally on a daily level: stress (Kossek et al., 2006; Mann \& Holdsworth, 2003), work-to-home conflict (Allen et al., 2001; Delanoeije et al., 2019; Hammer et al., 2005; Golden et al., 2006), work engagement (Richman et al., 2018; Sardeshmukh, Sharma \& Golden, 2012; ten Brummelhuis, Bakker, Hetland \& Heulemans, 2012) and job performance (Beauregard \& Henry, 2009; Casper et al., 2007; Hill et al., 1998; Vega et al., 2015; Windeler et al., 2017). In addition, all these outcomes have been found to change over larger periods of time (Bond \& Bunce, 2000; Kooij, Tims \& Akkermans, 2017; Rantanen, Kinnunen, Pulkkinen \& Kokko, 2012) as well as fluctuate on a daily basis (Ilies et al., 2007; Maertz \& Boyar, 2011; Petrou et al., 2012; Vega 
et al., 2015). Understanding whether telework indeed affects these outcomes on both a between-person and a within-person level or, conversely, on only one or none of these levels, may help to understand the mechanisms through which telework impacts employees. In what follows, we will first develop our person-level hypotheses and then our day-level hypotheses.

\section{Hypotheses}

\section{Hypotheses on person-level outcomes}

Person-level stress. Stress can be described as negative physical or emotional reactions in employees (Bentley et al., 2016). We expect that telework may decrease employees' personlevel stress. First of all, since telework gives employees more autonomy to decide when, where and how they work (Kossek et al., 2006), employees who are allowed to telework are often better able to schedule and conduct their work in a way they like. This job autonomy (Thompson \& Prottas, 2006) is likely to decrease stress since it functions as an additional resource to tackle high work demands (Bailey \& Kurland, 2002; Marshall, Barnett \& Sayer, 1997; Melchior et al., 2007). As such, employees are more likely to cope with work demands successfully when they feel that they have the necessary resources (Grawitch et al., 2010). Important to note is that enhanced schedule control may, at least for some employees, also increase stress, for instance since they do not have the ability for self-management or selfregulation (Demerouti et al. 2014; Schieman \& Young, 2010). Second, since telework reduces weekly commuting time, it may enable employees to invest more time in leisure activities to recover from work (Bentley et al., 2016; Stephens \& Szajna, 1998). Even if these recoveractivities do not happen every day, individuals who feel in control over how they allocate their resources between their work activities and other activities are able to self-regulate their resources successfully, which may decrease their person-level stress (Grawitch et al., 2010). Indeed, if the general job demands match the resources of the employee, person-level stress is 
less likely to emerge (Parent-Thirion et al., 2016). We therefore expect that once employees are allowed to telework, their person-level stress will lower:

Hypothesis 1: Person-level stress will decrease when employees are allowed to telework. Person-level work-to-home conflict. Work-to-home conflict is the conflict that occurs when the time people devote to their work role precludes meeting the demands in the home role (time-based conflict) or when they experience stress or strain in their work role that hinders them in meeting the demands of the home role (strain-based conflict) (Greenhaus and Beutell, 1985). We expect that telework may decrease people's person-level work-to-home conflict because an increased scheduling autonomy of telework enables teleworkers to arrange their work demands around their home demands (Beauregard \& Henry, 2009; Golden et al., 2006). Indeed, one of the most common reasons employees give for teleworking is to combine work with private life more easily (Allen et al., 2015). If employees are enabled to align their work schedule with their preferred working schedule - for instance, teleworking on days they have to pick up the kids from school—-telework may increase employees' time to spend with their family and to meet their home responsibilities in general (Allen et al., 2015; Golden et al., 2006; Major, Klein \& Ehrhart, 2002; Standen et al., 1999). This may result in lowered workto-home conflict (Golden et al., 2006; Madsen, 2003; Voydanoff, 2005). Importantly, some studies have also found the opposite, i.e. an increase in work-to-home conflict due to telework since employees may experience negative spillover from work to home and may extend their working hours (Greer \& Payne, 2014; Golden, 2012; Hill, Miller, Weiner \& Colihan, 1998). However, recent meta-analytic evidence shows small but significant negative effect sizes $(r)$ of -.16 (Gajendran \& Harrison, 2007) and of -.08 (Allen et al., 2013) for work-to-home conflict. We therefore expect that employees will experience a reduction in work-to-home conflict after they are allowed to telework: 
Hypothesis 2: Person-level time-based work-to-home conflict and person-level strainbased work-to-home conflict will decrease when employees are allowed to telework. Person-level work engagement. Work engagement is defined as a "positive, fulfilling workrelated state of mind that is characterized by vigor, dedication, and absorption" (Schaufeli, Bakker \& Salanova, 2006, p. 702). As a family-friendly work arrangement (Delanoeije et al., 2019), telework may increase general work engagement by means of social exchange (Blau, 1964). As such, if employees experience that their organization cares for them and trust them to work from home, they may return this with positive attitudes and behaviors (Kooij et al., 2013), such as increased person-level work engagement (Bakker \& Schaufeli, 2008). Organizational support (Richman et al., 2008) and felt trust (Skiba \& Wildman, 2019) have indeed been found to be important antecedents of person-level work engagement. In addition, having autonomy over where and how to work, which telework entails, has been positively linked with person-level work engagement (Anderson \& Kelliher, 2009). However, it is important to note that telework has also been linked with lower work engagement because employees who work from home may get less feedback and perceive higher role ambiguity (Sardeshmukh, Sharma \& Golden, 2012). Departing from a resource perspective of telework due to enhanced autonomy (Kossek et al., 2006; Sardeshmukh, Sharma \& Golden, 2012), we expect that employees will experience an increase in work engagement after being allowed to telework:

Hypothesis 3: Person-level work engagement will increase when employees are allowed to telework.

Person-level job performance. Job performance refers to "a worker's effective execution of tasks or job and useful contribution to the social work environment" (Abramis, 1994, p. 549). Telework may increase person-level job performance. First, based on social exchange theory (Blau, 1964), employees who feel treated favorably by their organization will feel they have 
to exchange this with positive attitudes and behaviors, such as by increased job performance (Appelbaum et al., 2000; Kooij et al., 2000). Second, employees who are allowed to telework may perceive more supervisor support (Lapierre \& Allen, 2006) which may empower them to reach work goals and increase job performance (Huang 2012; Thomas et al., 2009)—for instance through seeking out feedback with supportive supervisors (Huang, 2012). While employees may also experience less job performance due to social isolation and less feedback (Golden, Veiga \& Dino, 2008; Sardeshmukh, Sharma \& Golden, 2012), we depart from a resource perspective of telework through enhanced autonomy and control (Kossek et al., 2006) and hypothesize that employees will report increased job performance after they are allowed to telework:

Hypothesis 4: Person-level job performance will increase when employees are allowed to telework.

\section{Hypotheses on day-level outcomes}

Day-level stress. We expect that telework may decrease employees' day-level stress. On teleworking days, employees are likely to experience more flexibility (Anderson et al., 2014; Moen, Kelly, Tranby \& Huang, 2011) which may function as an additional resource to tackle the work demands on that specific day (Bailey \& Kurland, 2002; Marshall, Barnett \& Sayer, 1997; Melchior et al., 2007) and could in that way result in less stress on that day (Moen et al., 2011). In addition, employees are likely to experience less commuting stress (Evans, Wener \& Phillips, 2002; Peters, Tijdens, \& Wetzels, 2004) and less interruptions from colleagues on teleworking days (Windeler et al., 2017), which may also result in less daylevel stress on teleworking days (Costal, Pickup \& Di Martino, 1988; Jett \& George, 2003). We therefore hypothesize:

Hypothesis 5: Day-level stress is lower on teleworking days compared to nonteleworking days. 
Day-level work-to-home conflict. We expect that work-to-home conflict will be lower on teleworking days compared to non-teleworking days. First, telework allows employees to interrupt their work role to address some home tasks during work hours (Delanoeije et al., 2019; Golden et al., 2006), which may reduce people's work-to-home conflict on that specific day (Ashforth, Reiner \& Fugate, 2000; Delanoeije et al., 2019; Kelly et al., 2008; Voydanoff, 2005). Indeed, recent research has found teleworking days to be related with less daily workto-home conflict, and this effect was partially mediated by transitions from the work domain to the home domain on teleworking days (Delanoeije et al., 2019). In addition, since employees are able to adjust their work hours to their home tasks on teleworking days (Golden et al., 2006), employees are likely to feel more in control of the interactions between their different life domains on that day, which is believed to reduce negative spillover effects from one domain to the other (Zedeck \& Mosier, 1990). For example, if employees experience work-related problems, negative spillover to the home domain is less likely to occur because employees working from home have the control over when to stop or start addressing work demands and stop and start addressing home demands. Based upon the above, we hypothesize:

Hypothesis 6: Day-level time-based work-to-home conflict and day-level strain-based work-to-home conflict are lower on teleworking days compared to non-teleworking days. Day-level work engagement. We expect that work engagement will be higher on teleworking days compared to non-teleworking days. When working from home, employees have discretion over the way or the timing in which they execute their working tasks that day compared to office days. This task-specific autonomy may serve as an important job resource, increasing work engagement that day (De Spiegelaere, Van Gyes \& Van Hootegem, 2016; Sonnentag, Dormann \& Demerouti, 2010). Daily job autonomy has repeatedly been found as an important antecedent for daily work engagement (e.g., Kühnel, Sonnentag \& Bledow, 
2012; Xanthopoulou et al., 2009; for an overview, see Bakker, 2014). Relatedly, employees may increase self-management on teleworking days, as there is no direct supervision on these days. Previous research has found a positive relationship between daily self-management and daily work engagement (Breevaart, Bakker \& Demerouti, 2014). In line with the above, one study has indeed found higher work engagement on days employees work from home (ten Brummelhuis, Bakker, Hetland \& Heulemans, 2012). We therefore hypothesize:

Hypothesis 7: Day-level work engagement is higher on teleworking days compared to non-teleworking days.

Day-level job performance. We expect that employees will report higher job performance on days they work from home compared to days they work at the office. Among the most common reasons that employees give for teleworking is the wish to work more productively and get more work done on these days (Allen et al., 2015; Anderson \& Kelliher, 2009). When working from home, employees can work without interruptions from colleagues (Mann \& Holdsworth, 2003) and, therefore, working from home may enhance focus and increase employees' control over how to structure and fulfill their daily working tasks (Bakker \& Demerouti, 2008). Studies have indeed suggested (Bailey \& Kurland, 2002; Duxbury \& Neufeld 1999) and found (Vega et al., 2015; Smit et al., 2016; Windeler et al., 2017) that working from home may increase day-level job performance, for instance through decreased interruptions from colleagues (Smit et al., 2016; Windeler et al., 2017). In addition, the time that is saved by not having to commute to work, may be spent on working tasks (Apgar, 1998). Based on these arguments, we hypothesize:

Hypothesis 8: Day-level job performance will decrease on days teleworkers work from home compared to days they do not work from home.

\section{Materials and methods}


This study was conducted in a large international construction and property development firm that has its headquarters in Brussels, the capital of Belgium. The aim of the study was to evaluate a pilot initiative that allowed home-based telework in two departments in the headquarters of this company during a period of three months, from mid-April to mid-July. Before this study, employees in this company (and in these departments) were allowed to telework on an ad hoc basis (e.g., to care for a sick child or in case of bad weather). The idea of a more systematic telework policy was introduced by a group of mid-level managers who, as part of a master business class, had worked out the business case for a systematic telework policy. They argued that telework could both enhance time-efficiency of the current employees who would have to commute less and be an asset to attract new - in particularly young - employees, who increasingly value flexibility and work-home balance (Randstad, 2017). This group of mid-level managers presented their ideas to the board of the company, who agreed upon a pilot initiative to explore the impact of telework on employee functioning (i.e., wellbeing and performance). Given the rather conservative culture in this company, the introduction of telework would imply a significant change for this company and therefore, the board wanted to understand well its impact before deciding about the introduction of a telework policy for the whole company. The board selected two departments in the headquarters (i.e., the engineering and the estimating departments) that could be part of the pilot initiative and decided to allow telework on two fixed days a week, i.e., on Tuesday and Thursday (which are the days with most traffic to and from Brussels), during a period of three months. We were contacted by the group of mid-level managers, who were organizing the pilot initiative, to conduct an evaluation of this initiative.

\section{Procedure and design}

We opted for an intervention group-control group design. This design allowed us to control for history effects (i.e., the influence of other events and changes in the company, which could 
affect the intervention and the control group in a similar way; Cook et al., 2002). The two department heads assigned their employees to either the intervention group (i.e., employees who were allowed to work from home at most two day a week) or the control group (i.e., a non-teleworking group with no change in telework policy) based on the employees' daily commuting time (i.e., needs-based assignment) and their job performance. The latter criterion was taken into account since the supervisors wanted to trust the teleworking employees that they were able to do their job well without being monitored directly. These two criteria (i.e., commuting time and job performance) are likely to be a good reflection of how telework allowance decisions are made in many organizations (Lembrechts et al., 2016; Poelmans \& Beham, 2008; Windeler et al., 2017).

The evaluation of the pilot initiative consisted of two parts. The first part concerned a pretest-posttest study to examine general changes in employee functioning due to the allowance of telework. To this end, we collected survey data at two points in time, i.e. before the start of the pilot initiative (T1) and near the end of the three-month intervention period (T2). The second part of the evaluation concerned a daily diary study to examine the withinperson changes due to having worked from home on a given day. To examine the daily effects, we collected daily diary data during 13 consecutive working days.

Of the 78 participants who completed the survey at T1, 64 participants (34 in the teleworking group and 30 in the control group) also completed the survey at T2 (response rate $=83 \%$ ). We did not find significant differences on background variables (i.e., autonomy, commuting time, gender, age, having a partner, amount of children) and baseline measures of our study variables between respondents who filled out the survey at T2 and respondents who did not fill out the survey at T2. It should be noted, however, that the lack of observing differences may be due to our rather small sample size. We did find a difference for department $\left(F(1,72)=13.75, p<.001, \eta^{2}=.12\right)$, since more employees from the Estimating 
Department did not fill in the survey at T2 compared to employees from the Engineering Department. The number of respondents to the daily surveys ranged from 29 (37.2\%) to 68 (87.2\%), and respondents filled out the daily questionnaire between 2 and 13 times in total $(M$ $=9.62, S D=3.71)$, resulting in 741 out of 1001 possible observations $(74 \%)$.

\section{Description of the sample}

Of the initial 78 respondents, $50 \%$ were in the intervention group. Most of the respondents (75.7\%) worked in the Engineering Department. The majority of the sample was male (75.6\%) and worked full-time (87.2\%). Study participants held jobs at various hierarchical levels with a range of job titles including senior calculator, tender manager, bid manager, prequalification officer, and technician. Tenure ranged from 0 to 45 years $(M=10.50, S D=$ 9.10). Respondents had zero to four children $(M=1.23, S D=1.10)$ and 58 respondents (74.4\%) indicated to live together with a partner.

We tested whether the employees in the control group differed from their teleworking colleagues on background characteristics and on the baseline measures of our study variables. No significant differences were found in department, gender, age, having a partner, amount of children, stress, work-to-home conflict or work engagement. It should be noted that the lack of observing differences in the background characteristics or baseline measures should be approached with caution because of the small sample size and, accordingly, the low power. Employees in the control group did differ from their teleworking colleagues with respect to commuting time $\left(F(1,73)=17.35, p<.001, \eta^{2}=.05\right)$ and self-reported performance at $\mathrm{T} 1$ $\left(F(1,74)=6.30, p=0.01, \eta^{2}<.01\right)$. These differences are consistent with the fact that the assignment of employees to the teleworking group was based upon employees' need for telework (i.e., longer commuting times) and on their performance. To take into account these differences at $\mathrm{T} 1$, we report the results both without and including the covariate of commuting time (i.e. MANCOVA) (since baseline performance is already included in our repeated 
measures MANOVA analysis). For work-to-home conflict, work engagement and job performance, the analyses with and without control variables yielded the same results; for stress, results were different. In our daily within-person analyses, we report the results without controls of commuting time and baseline job performance since results were similar in both analyses with and without controls.

\section{Trait measures}

Group. Group is a dummy-variable which is coded 1 if the respondent was part of the intervention group (i.e., employees who were allowed to telework on 2 fixed days a week, i.e. Tuesday and Thursday) and 0 if the respondent was part of the control group (i.e., employees who were not allowed to telework on a weekly basis).

Stress. We measured stress at T1 and T2 using 5 items of the General Health Questionnaire by Goldberg and Hillier (1979) $(\alpha \mathrm{T} 1=.77, \alpha \mathrm{T} 2=.86)$. A sample item is "To which extent have you been nervous in the past month?". The response scale ranged from 1 (Totally not) to 7 (Totally).

Work-to-home conflict. Work-to-home conflict was measured at T1 and T2 using the threeitem scales of Carlson, Kacmar and Williams (2000) for time-based work-to-home conflict $(\alpha \mathrm{T} 1=.88, \alpha \mathrm{T} 2=.94)$ and strain-based work-to-home conflict $(\alpha \mathrm{T} 1=.86, \alpha \mathrm{T} 2=.91) . \mathrm{We}$ replaced "family" by "private life". Sample items are "The time I must devote to my job keeps me from participating equally in the household" (time-based work-to-home conflict) and "I am often so emotionally drained when I get home from work that it prevents me from contributing to my private life activities/responsibilities" (strain-based work-to-home conflict). The response scale ranged from 1 (Totally disagree) to 7 (Totally agree).

Work engagement. Work engagement was measured at $\mathrm{T} 1$ and $\mathrm{T} 2 \mathrm{using}$ six items of the nine item work engagement scale of Schaufeli et al. $(2006)(\alpha \mathrm{T} 1=.89, \alpha \mathrm{T} 2=.93)$. To reduce respondent fatigue, we selected the vigor and the dedication subscale (three items each) and 
left out the work absorption scale (three items). Since both the vigor and the absorption scale are considered to be task-specific facets of work engagement, whereas dedication is seen as a job specific facet (Sonnentag, 2017), our choice for vigor and dedication allowed us to capture, in fewer items, both task specific and job specific aspects of the original scale. Sample items are "At work, I burst of energy" and "I am enthusiastic about my job". The response scale ranged from 1 (Totally disagree) to 7 (Totally agree).

Job performance. We measured self-reported job performance at T1 and T2 using the sixitem scale from Abramis $(1994)(\alpha \mathrm{T} 1=.84, \alpha \mathrm{T} 2=.88)$. Sample items are "How well did you, in your own opinion, took responsibility during the last work week?" and "How well did you, in your own opinion, reach your goals during the last work week?". The response scale ranged from 1 (Very bad) to 7 (Very good).

\section{State measures}

Teleworking day, stress, work-to-home conflict, work engagement and job performance were all measured in the daily surveys. The measures we used in the daily surveys were in general shortened versions of the measures we used in the general questionnaires in order to lower fatigue. In addition, we adapted the items to the daily level (for a similar approach: see Ilies et al., 2017).

Teleworking day. Teleworking day is a dummy-variable, which is 1 if respondents indicated in the daily survey that they had worked from home that day during the regular working hours, and 0 otherwise. Respondents who had not worked that day, for instance due to illness, were coded as missing.

Daily stress. To measure daily stress, we adapted the 5 items to capture stress from the General Health Questionnaire of Goldberg and Hillier (1979) to daily items. A sample item is “To which extent have you been nervous today?". The response scale ranged from 1 (Totally not) to 7 (Totally). Multilevel reliability, expressed in the generalizability coefficient of 
average time points across all items (Revelle \& Wilt, 2019; Shrout \& Lane, 2012) was .84, with the daily Cronbach's $\alpha$ ranging from .79 to .89 . Moreover, multilevel confirmatory factor analysis showed that all factor loadings were between .52 and .60 , i.e. the latent factor explained between $27 \%$ and $36 \%$ of the variance in the items (Brown, 2015).

Daily work-to-home conflict. We measured daily work-to-home conflict using a shortened and slightly adapted version of the Carlson et al. (2000) scale. In line with Delanoeije et al. (2019), to decrease respondent fatigue, we used two out of three highest loading items of the strain-based conflict scale and two of the three highest loading items of the time-based conflict scale, resulting in four items. Items were adjusted to day-level measurement. The two items for time-based work-to-home conflict were: (1) "Today, I had to miss activities in my private life due to the amount of time I had spent working", (2) "Today, the time I spent on work responsibilities interfered with my responsibilities in my private life". The two items for strain-based work-to-home conflict were: (1) “Today, after work, I was so emotionally drained that it prevented me from contributing in my private life", and (2) “Today, after work, I was too stressed to do the things I enjoy due to all the pressures at work". Respondents were asked to indicate the extent to which they agreed with the given statement on a scale from 1 (Strongly disagree) to 7 (Strongly agree). Multilevel reliability, expressed in the generalizability coefficient of average time points across all items (Revelle \& Wilt, 2019; Shrout \& Lane, 2012) was .81, with daily Cronbach's $\alpha$ ranging from .76 to .95. Multilevel confirmatory actor analysis showed that factor loadings were between .84 and .94 , i.e. the latent factor explained between $71 \%$ and $88 \%$ of the variance in the items (Brown, 2015). Daily work engagement. To measure daily work engagement, we adapted the 6 items of the scale of Schaufeli et al. (2006) to daily items. Sample items are "Today at work, I burst of energy" and "Today, when I got up in the morning, I felt like going to work". The response scale ranged from 1 (Totally disagree) to 7 (Totally agree). Multilevel reliability, expressed in 
the generalizability coefficient of average time points across all items (Revelle \& Wilt, 2019; Shrout \& Lane, 2012) was .93, with daily Cronbach's $\alpha$ ranging from .90 to .95 . Multilevel confirmatory actor analysis showed that factor loadings were between .65 and .79 , i.e. the latent factor explained between $42 \%$ and $62 \%$ of the variance in the items (Brown, 2015). Daily job performance. To measure daily job performance, we used 3 of the 6 items of the scale from Abramis (1994) and adapted them to daily items. Sample items are "How well did you, in your own opinion, took responsibility today?" and "How well did you, in your own opinion, reach your goals today?". The response scale ranged from 1 (Very bad) to 7 (Very good). Multilevel reliability, expressed in the generalizability coefficient of average time points across all items (Revelle \& Wilt, 2019; Shrout \& Lane, 2012) was .83, with daily Cronbach's $\alpha$ ranging from .70 to .90 . Multilevel confirmatory actor analysis showed that factor loadings were between .60 and .81 , i.e. the latent factor explained between $36 \%$ and $66 \%$ of the variance in the items (Brown, 2015).

\section{Strategy of analysis}

To analyze the pretest-posttest data, we performed a repeated measures MANOVA in SPSS with time (i.e. pretest and posttest measurement occasion) as the within-subject variable and group as the between-subject variable. In addition, we calculated partial eta-squared $\left(\eta_{p}{ }^{2}\right)$ effect sizes, i.e. the variance explained by a given variable of the variance remaining after excluding variance explained by other predictors (Levine \& Hullett, 2002). Partial eta-squared effect sizes can be interpreted as a small effect if $.01 \leq \eta_{p}{ }^{2}<.06$, a medium effect if $.06 \leq \eta_{p}{ }^{2}$ $<.14$, and a large effect if $\eta_{p}{ }^{2} \geq .14$ (Cohen, 1988; Miles \& Shevlin, 2001). Partial eta squared is suitable for comparisons of effects within a single study (Lakens, 2013; Olejnik \& Algina, 2003) and is suitable for a repeated measures MANOVA design (Brown, 2008). All in all, effect sizes in the social sciences are often very small and there is no consensus on what magnitude is necessary to establish practical significance (Bosco et al., 2014; Ferguson, 2009; 
Rosnow \& Rosenthal, 2003). Moreover, it should be noted that we had a very small sample size (i.e. $N=34$ for the teleworking group and $N=30$ for the control group), making the likelihood of observing of between-person effects - even with small or medium effect sizes considerably small. Due to the small sample size, the observed effects sizes should be approached with some caution since we may not be able to get a precise estimate of the effects and their effect sizes.

To examine the daily effects, we performed linear mixed coefficient modeling (MCM) in R. MCM takes into account the nested structure of the daily data, with repeated measurements (daily variables) at the first level ( $N=741$ occasions) and individuals at the second level $(N=$ 78 respondents). We employed restricted maximum likelihood (REML) estimation, as this restricted form of maximum likelihood (ML) estimation is more suitable for complex datasets including multiple fixed effects (Corbeil \& Searle, 1976; Gilmour et al., 1995). Contrary to ML, REML estimation does not expect all fixed effects to be known without errors and maximizes only the portion of the likelihood not depending on the fixed effects. Moreover, to estimate effect size of the used model, we calculate the likelihood ratio obtained through model comparison between the general linear model, the null model and the used model (excluding cases with missing values on one of the predictor variables to allow for model comparison). For this calculation, we used ML estimation because models with different fixed effects cannot be meaningfully compared using REML estimation (Wood, 2011).

Following the guidelines of Aguinis, Gottfredson and Culpepper (2013) and of Lischetzke, Reis, and Arndt (2015), we centered level two predictor variables to the grand mean. By this means, we estimate pure within-person effects and control for between-person varying confounds (Lischetzke et al., 2015). We did not center teleworking day to facilitate interpretation of the coefficients (i.e. comparing teleworking day with non-teleworking days).

\section{Results}




\section{Comparison between $\mathrm{T1}$ and $\mathrm{T} 2$}

Table 1 shows the descriptives and correlations of the person-level variables. Table 2 gives an overview of the means at T1 and T2 on the outcomes under study (stress, time-based work-tohome conflict, strain-based work-to-home conflict, work engagement and job performance) for both the teleworking group and the control group, as well as the effect sizes and observed power in the MANOVA analysis.

\section{$<$ INSERT TABLES 1 AND 2 ABOUT HERE >}

In the MANOVA analysis without control variables, the multivariate result was significant for the within-person effect of time (i.e. pretest-posttest measurement) $(F(5,58)=3.53, p=.01$, $\left.\eta_{p}{ }^{2}=.23\right)$ yet not for the interaction of time with group $\left(F(5,58)=1.02, p=.42, \eta_{p}{ }^{2}=.08\right)$, indicating that for none of the measured outcomes, the change over time differed between the teleworking group and the control group. The univariate $\mathrm{F}$ tests showed there was a significant interaction effect between time and group for stress $\left(F(1,62)=4.21, p=.04, \eta_{p}{ }^{2}=\right.$ .06) but no significant interaction effects of time and group for time-based work-to-home conflict $\left(F(1,62)=0.27, p=.61, \eta_{p}^{2}<.01\right)$, strain-based work-to-home conflict $(F(1,62)=$ $\left.0.50, p=.49, \eta_{p}^{2}=.01\right)$, work engagement $\left(F(1,62)=0.36, p=.55, \eta_{p}^{2}=.01\right)$ or job performance $\left(F(1,62)=0.40, p=.53, \eta_{p}^{2}=.01\right)$.

In the MANCOVA analysis including commuting time as a covariate, the multivariate result was not significant for the within-person effect of time $\left(F(5,56)=0.71, p=.62, \eta_{p}{ }^{2}=\right.$ $.01)$ nor for the interaction of time with group $\left(F(5,56)=.65, p=.66, \eta_{p}{ }^{2}=.06\right)$. Moreover, none of the univariate tests was significant, indicating no interaction between time and group for stress $\left(F(1,62)=2.56, p=.11, \eta_{p}{ }^{2}=.04\right)$, time-based work-to-home conflict $(F(1,62)=$ $\left.0.27, p=.61, \eta_{p}^{2}<.01\right)$, strain-based work-to-home conflict $\left(\mathrm{F}(1,62)=0.33, p=.57, \eta_{p}^{2}<\right.$ $.01)$, work engagement $\left(F(1,62)=0.17, p=.68, \eta_{p}{ }^{2}<.01\right)$ or job performance $(F(1,62)=$ 
$\left.0.34, p=.56, \eta_{p}^{2}<.01\right)$. Hence, pre-existing differences in commuting time account for the earlier observed significant pretest-posttest decrease in the teleworking group that was not present in the control group.

\section{Daily within-person effects}

Table 3 shows the descriptives and correlations of the daily-level variables. Table 4 shows the results of the multilevel analyses to predict daily stress (Model 1), daily time-based work-tohome conflict (Model 2), daily strain-based work-to-home conflict (Model 3), daily work engagement (Model 4), and daily job performance (Model 5). As can be seen in this table, $43 \%$ of the variance in daily stress, $44 \%$ of the variance in daily time-based work-to-home conflict, $55 \%$ of the variance in daily strain-based work-to-home conflict, $42 \%$ of the variance in work engagement and $49 \%$ of the variance in job performance is due to within-person variation. This supports our choice for multilevel analyses as this remaining variance may be due to daily fluctuations in work location. Moreover, model comparison indicated that our multilevel model with covariates had a better fit compared to the null model (i.e., multilevel, no covariates) (stress: $\chi^{2}(2)=49.88, p<.001$; time-based work-to-home conflict: $\chi^{2}(2)=$ $12.45, p<.001$; strain-based work-to-home conflict: $\chi^{2}(2)=12.78, p<.001$; work engagement: $\chi^{2}(2)=30.46, p<.001$; time-based work-to-home conflict: $\chi^{2}(2)=28.10, p<$ .001 - see Table 4).

\section{< INSERT TABLES 3 AND 4 ABOUT HERE >}

Hypothesis 5 predicted that the intervention group would have less daily stress on a teleworking day compared to a non-teleworking day. As can be seen in Table 4 (Model 1), the standardized estimate of teleworking day on daily stress $(\gamma=-0.20, p<.001)$ was negative and significant, supporting hypothesis 5. Hypothesis 6 predicted that employees would experience less daily time-based and strain-based work-to-home conflict on a teleworking day compared to a non-teleworking day. The standardized estimates of teleworking day on daily 
time-based work-to-home conflict $(\gamma=-0.12, p<.001-$ see Table 4, Model 2) and on daily strain-based work-to-home conflict $(\gamma=-0.12, p<.001-$ see Table 4, Model 3) were significant; thus, hypothesis 6 is supported. Hypothesis 7 predicted that employees would show more work engagement on a teleworking day compared to a non-teleworking day, which is supported by the positive and significant standardized estimate of teleworking day to predict work engagement in Model $4(\gamma=0.14, p<.001)$. Finally, hypothesis 8 predicted that employees would have higher job performance on a teleworking day compared to a nonteleworking day, which is again supported in the positive and significant standardized estimate of teleworking day in Model $5(\gamma=0.18, p<.001)$. Also note that the dummy "group" was not significant in any of the models. This shows that on office days, employees in the teleworking group and employees in the control group report similar levels of daily stress, work-to-home conflict, work engagement and job performance.

\section{Discussion}

In this study, we examined both person-level and day-level effects of telework using a quasiexperimental design. In that way, our study responds to the various calls in the literature to use intervention studies to understand better the impact of telework (Allen et al., 2015; Antonakis et al. 2010; Brough \& O’Driscoll, 2010). Thanks to our design, we are able to rule out selection (reversed causality) effects as an alternative explanation for our findings. In addition, by examining both person-level and daily-level effects, our study can help to further our understanding of how telework affects employee outcomes. However, it is important to note that our between-person results are underpowered and therefore the effect size estimates are most likely biased, resulting in less trustworthy results compared to the within-person results.

For stress, we found both person-level and daily-level effects of telework. So, employees reported both a significant decrease in general stress-levels after they were allowed to 
telework compared to before the onset of the telework intervention and lower daily stresslevels on teleworking days compared to office days. The daily effect may be due to the reduction of daily stressors on teleworking days, such as less commuting time (Evans, Wener \& Phillips, 2002) or less interruptions of colleagues (Windeler et al., 2017). The betweenperson effect is likely due to ex-ante differences in commuting time since this effect disappeared when we controlled for commuting time at T1. So, the teleworkers in our study are likely to have less stress after the introduction of telework because they now have to commute less. Note that we observed only a small effect size for the person-level effect of stress. According to Bosco et al. (2015), small effect sizes may indicate that the mechanism of the intervention may be not well enough understood and according to Funder \& Ozer (2019), very small effect sizes may indicate small effects for single events (i.e. our intervention), but these may be consequential in the long run . Since our outcome variables were rather distal from the intervention (i.e. the outcomes are affected by a wide variety of work- and homerelated factors that were not affected by the intervention), effect sizes may anyway be small (Funder \& Ozer, 2019).

For work-to-home conflict, we found no person-level effects but we did find negative daily-level effects of telework. Possibly, the lack of a person-level effect could be explained by our small sample size. Alternatively, employees in this company may not have experienced more overall flexibility which could help them to combine their work and home responsibilities and may therefore result in lowered person-level work-to-home conflict. This may be because they were not experienced enough in teleworking and optimally using increased flexibility (Bailey \& Kurland, 2002; Ashforth et al., 2002) or because of work-home boundary role blurring (Ashforth et al., 2000; Hill, Miller, Weiner, \& Colihan, 1998), which has been found to increase work-to-home conflict (Glavin \& Schieman, 2012) and has been 
put forward as an important risk of telework for employees' work-to-home conflict (Ashforth et al., 2000).

For both work engagement and job performance, we found daily-level effects but no person-level effects of telework. So, although employees who are allowed to telework report higher levels of daily work engagement and daily job performance on teleworking days compared to office days, their general level of work engagement and job performance did not change after they were allowed to telework compared to their levels before the onset of the telework intervention. Our daily analyses confirm two earlier studies that found higher work engagement (ten Brummelhuis et al., 2012) and higher job performance (Vega et al., 2015) on teleworking days. On these days, employees have control over how to structure work tasks (De Spiegelaere et al., 2016) and encounter less interruptions from colleagues or a crowded office environment (Windeler et al., 2017), which may explain increased work engagement and job performance on these days. As noted earlier, our small sample size may explain the lack of person-level effect. Otherwise, this lack may imply that the mechanism of social exchange, which if often put forward as explanation to expect person-level effects on work engagement and job performance (de Menezes \& Kelliher, 2011; Kossek et al., 2011), is not at play here. Because telework is becoming more current in recent decades (Allen et al., 2015), it is possible that employees may no longer perceive the allowance to telework as a favor from their organization which they have to reciprocate, but rather as an entitlement or as a right (Beauregard \& Henry, 2009). Alternatively, the result could be related with the specific setting of our study. In particular, the telework intervention was a pilot initiative that would only last for three months (after which the board of the organization would evaluate it and decide about implementing an overall teleworking policy for the whole company or not). This limited time horizon could have made employees more reserved and less inclined to reciprocate. Since we hypothesized that the daily effects of telework on daily job performance 
are explained by enhanced productivity (e.g. because of less work interruptions or an employee-tailored structure of the working day), these effects are not affected by loss of social exchange.

\section{Theoretical and practical implications}

Our findings that telework has important daily effects may stimulate researchers and organizations to rethink how they evaluate the effects of telework. More specifically, our results show that when only person-level effects are considered, organizations may wrongly conclude that telework is ineffective regarding certain outcomes. For instance, we found no person-level effect of telework on time-based and strain-based work-to-home conflict, work engagement and job performance - which may be explained by the small sample size and the lack of power - yet teleworkers reported more work engagement and higher job performance on teleworking days compared to office days. So, even though the daily effects may not always materialize in general changes (or may not be observed using a small sample), they are important because they point to a facilitated daily management. As such, understanding the daily impact of telework may help practitioners to take more informed implementation and allowance decisions, especially since we know that managers are sometimes reluctant to allow telework since they fear difficulties in the daily management of teleworking employees, jeopardizing their output and/or performance (Poelmans \& Beham, 2008).

Second, researchers may want to be aware of selection effects in the use of telework, for which we found indications in our study. Such selection effects may bias conclusions from research on telework that uses a non-experimental design (including multiple-wave studies). Also organizations need to be aware of such effects. Being aware of selection effects could help to make managers aware of the risk of only making policies available for those employees already high in specific resources (e.g., autonomy) or skills (Gray \& Tudball, 2003), hereby limiting other employees' chances to facilitate combining work with private 
life. Given the paradox that employees who need work-home policies the most are often not the ones who are granted access to these policies (Glass \& Finley, 2002; Gray \& Tudball, 2003), organizations may want to be aware of existing biases and consider loosening their criteria for allowing access to work-home policies. This could allow for the potential benefits of these policies to reach more employees.

Overall, our study revealed several benefits of telework on employee outcomes, both at the person-level and at the daily level. This may encourage organizations considering implementing this HR policy. Based on our results, the organization in this study decided to implement home-based telework within the whole company a couple of months after the end of the pilot.

\section{Limitations}

The main limitation of this study is that the one-company case design leads to low external validity of the findings. Hence, we suggest caution when generalizing our findings towards other types of implementations and companies because we cannot rule out that our findings are related with the specific choices concerning telework within this organization (e.g., allowing to telework on two fixed days a week; the duration of the pilot: three months). Second, in our pretest-posttest design, the small sample size and lack of power limits the extent to which conclusions can be drawn about not observing significant effects. Future research should seek to replicate our design in bigger sample sizes since the small sample size of the teleworking group $(N=34)$ and the control group $(N=30)$ is likely underpowered for detecting small effect sizes. Third, for three of our four daily measurements, we used shortened versions of validated scales. Whereas we checked reliability in all used scales, validity of these scales may not be warranted. Fourth, all measures were self-reported, which may lead to common-method bias (Siemsen et al., 2010). Especially in the case of performance, research may benefit from using objective measures (Beauregard \& Henry, 
2009). Fifth, we did not include any measures of fairness in our study. Since fairness of telework decisions may affect the effects of telework on employee outcomes (Poelmans \& Beham, 2008) and non-teleworking employees in our study were aware of a teleworking group that was allowed to telework, this may have affected our results in the control group. Relatedly, employees in the teleworking group may have been motivated to respond more favorably to the surveys since they were aware the study concerned the evaluation of the initiative. Last, since we found a difference in baseline performance between our teleworking group and our control group, we suggest some caution when interpreting our findings. While it is likely that selection effects based on performance also exist in allowance decisions for telework (Poelmans \& Beham, 2008), the effects we found for employees in our teleworking group may not translate to low-performing employees. As such, our study should be considered within its limitations: we have exemplified some of the effects that a telework policy can create under certain boundary conditions rather than that we have searched for universal effects of a telework intervention.

\section{Conclusion}

This study examined the impact of telework on employees' person-level and day-level stress, work-to-home conflict, work engagement and job performance using a quasi-field experiment. Our results provided support for within-person but no multivariate betweenperson effects of telework, yet our between-person design was likely to be underpowered to observe between-person effects. In particular, on a person level, only univariate analysis showed that employees who were allowed to telework had less stress compared to when they were not allowed to telework before, but no differences in work-to-home conflict, work engagement or job performance were found over time. On a day level, teleworkers reported lower stress, lower work-to-home conflict, higher work engagement and higher job performance on teleworking days compared to non-teleworking days. There were no 
differences between teleworkers and non-teleworkers on these outcomes on non-teleworking days. We therefore encourage scholars and practitioners to use different levels of analysis when studying or evaluating telework policies since effects between employees and effects within employees may not necessarily be the same.

\section{References}

Abramis, D. (1994). Relationship of job stressors to job performance: Linear or an inverted-U? Psychological reports, 75(1), 547-558.

Aguinis, H., Gottfredson, R., \& Culpepper, S. (2013). Best-practice recommendations for estimating cross-level interaction effects using multilevel modeling. Journal of Management, 39(6), 1490-1528.

Allen, T., \& Eby, L. (Eds.). (2016). The Oxford handbook of work and family. New York, NY, US: Oxford University Press.

Allen, T., Golden, T., \& Shockley, K. (2015). How effective is telecommuting? Assessing the status of our scientific findings. Psychological Science in the Public Interest, 16(2), 40-68.

Allen, T., Herst, D., Bruck, C., \& Sutton, M. (2000). Consequences associated with work-tofamily conflict: A review and agenda for future research. Journal of Occupational Health Psychology, 5(2), 278-308.

Allen, D., Renn; R. \& Griffeth, R. (2003). The impact of telecommuting design on social systems, self-regulation, and role boundaries. Research in Personnel and Human Resources Management, 22, 125-164.

Anderson, A., Kaplan, S., \& Vega, R. (2014). The impact of telework on emotional experience: When, and for whom, does telework improve daily affective well-being? European Journal of Work and Organizational Psychology, 24(6), 882-897.

Anderson, D., \& Kelliher, C. (2009). Flexible working and engagement: The importance of choice. Strategic HR Review, 8(2), 13-18.

Antonakis, J., Bendahan, S., Jacquart, P., \& Lalive, R. (2010). On making causal claims: A review and recommendations. The Leadership Quarterly, 21(6), 1086-1120.

Apgar, M. (1998). The alternative workplace: Changing where and how people work. Harvard Business Review, 76, 121-136.

Ashforth, B., Kreiner, G., \& Fugate, M. (2000). All in a day's work: Boundaries and micro role transitions. Academy of Management Review, 25, 472-491.

Bailey, D., \& Kurland, N. (2002). A review of telework research: Findings, new directions, and lessons for the study of modern work. Journal of Organizational Behavior, 23(4), 383-400.

Bakker, A. (2014). Daily fluctuations in work engagement. European Psychologist, 19, 227 236.

Bakker, A., Demerouti, E., \& Verbeke, W. (2004). Using the job demands-resources model to predict burnout and performance. Human Resource Management, 43(1), 83-104. 
Bakker, A., \& Schaufeli, W. (2008). Positive organizational behavior: Engaged employees in flourishing organizations. Journal of Organizational Behavior, 29(2), 147-154.

Balogun, J., \& Hailey, V. (2008). Exploring strategic change. Pearson Education.

Beauregard, T., \& Henry, L. (2009). Making the link between work-life balance practices and organizational performance. Human Resource Management Review, 19(1), 9-22.

Bentley, T., Teo, S., McLeod, L., Tan, F., Bosua, R., \& Gloet, M. (2016). The role of organisational support in teleworker wellbeing: A socio-technical systems approach. Applied Ergonomics, 52, 207-215.

Boell, S., Cecez-Kecmanovic, D., \& Campbell, J. (2016). Telework paradoxes and practices: The importance of the nature of work. New Technology, Work and Employment, 31(2), 114 131.

Breevaart, K., Bakker, A., \& Demerouti, E. (2014). Daily self-management and employee work engagement. Journal of Vocational Behavior, 84(1), 31-38.

Brough, P., \& O'Driscoll, M. P. (2010). Organizational interventions for balancing work and home demands: An overview. Work \& Stress, 24(3), 280-297.

Brown, J. (2008). Effects size and eta squared. JALT Testing \& Evaluation SIG Newsletter, 12(2), 38-43.

Barnett, R., \& Brennan, R. (1995). The relationship between job experiences and psychological distress: A structural equation approach. Journal of Organizational Behavior, 16(3), 259276.

Bosco, F., Aguinis, H., Singh, K., Field, J., \& Pierce, C. (2015). Correlational effect size benchmarks. Journal of Applied Psychology, 100(2), 431-449.

Byron, K. (2005). A meta-analytic review of work-family conflict and its antecedents. Journal of Vocational Behavior, 67(2), 169-198.

Carlson, D., Kacmar, K., \& Williams, L. (2000). Construction and initial validation of a multidimensional measure of work-family conflict. Journal of Vocational Behavior, 56(2), 249-276.

Casper, W., \& Buffardi, L. (2004). Work-life benefits and job pursuit intentions: The role of anticipated organizational support. Journal of Vocational Behavior, 65(3), 391-410.

Casper, W., Eby, L., Bordeaux, C., Lockwood, A. \& Lambert, D. (2007). A review of research methods in IO/OB work-family research. Journal of Applied Psychology, 92(1), 28-43.

Chesley, N. (2005). Blurring boundaries? Linking technology use, spillover, individual distress, and family satisfaction. Journal of Marriage and Family, 67(5), 1237-1248.

Cohen, J. (1988). Statistical power analysis for the behavioral sciences (2nd ed.). Hillsdale, NJ: Erlbaum.

Cook, T., Campbell, D., \& Shadish, W. (2002). Experimental and quasi-experimental designs for generalized causal inference. Boston: Houghton Mifflin.

Corbeil, R., \& Searle, S. (1976). Restricted maximum likelihood (REML) estimation of variance components in the mixed model. Technometrics, 18(1), 31-38. 
Costal, G., Pickup, L., \& Di Martino, V. (1988). Commuting - a further stress factor for working people: evidence from the European Community. International Archives of Occupational and Environmental Health, 60(5), 377-385.

Daniels, K. (2006). Rethinking job characteristics in work stress research. Human Relations, 59(3), 267-290.

Delanoeije, J., Verbruggen, M., \& Germeys, L., (2019). Boundary role transitions: A day-today approach to explain the effects of home-based telework on work-to-home conflict and home-to-work conflict. Human Relations.

Demerouti, E., Bakker, A., Nachreiner, F., \& Schaufeli, W. (2001). The job demands-resources model of burnout. Journal of Applied Psychology, 86(3), 499-512.

Demerouti, E., Derks, D., Lieke, L., \& Bakker, A. B. (2014). New ways of working: Impact on working conditions, work-family balance, and well-being. In The impact of ICT on quality of working life (pp. 123-141). Springer, Dordrecht.

Demerouti, E., \& Cropanzano, R. (2010). From thought to action: Employee work engagement and job performance. In M. Leiter and A. Bakker, Work engagement: A handbook of essential theory and research (pp. 147-163). Psychology Press.

Demerouti, E., Derks, D., ten Brummelhuis, L., \& Bakker, A. (2014). New ways of working: Impact on working conditions, work-family balance, and well-being. In C. Korunka \& P. Hoonakker (Eds.), The impact of ICT on quality of working life (pp. 123-141). Netherlands: Springer.

De Spiegelaere, S., Van Gyes, G., \& Van Hootegem, G. (2016). Not all autonomy is the same. Different dimensions of job autonomy and their relation to work engagement $\&$ innovative work behavior. Human Factors and Ergonomics in Manufacturing \& Service Industries, $26(4), 515-527$.

Daniels, K., Lamond, D., \& Standen, P. (2001). Teleworking: frameworks for organizational research. Journal of Management Studies, 38(8), 1151-1185.

De Spiegelaere, S., Van Gyes, G., \& Van Hootegem, G. (2016). Not all autonomy is the same. Different dimensions of job autonomy and their relation to work engagement $\&$ innovative work behavior. Human Factors and Ergonomics in Manufacturing \& Service Industries, 26(4), 515-527.

Duxbury, L., \& Neufeld, D. (1999). An empirical evaluation of the impacts of telecommuting on intra-organizational communication. Journal of Engineering and Technology Management, 16(1), 1-28.

Evans, G., Wener, R., \& Phillips, D. (2002). The morning rush hour: Predictability and commuter stress. Environment and Behavior, 34(4), 521-530.

Funder, D., \& Ozer, D. (2019). Evaluating effect size in psychological research: Sense and nonsense. Advances in Methods and Practices in Psychological Science, 2(2), 156-168.

Gajendran, R., \& Harrison, D. (2007). The good, the bad, and the unknown about telecommuting: Meta-analysis of psychological mediators and individual consequences. Journal of Applied Psychology, 92(6), 1524-1541. 
Glavin, P., \& Schieman, S. (2012). Work-family role blurring and work-family conflict: The moderating influence of job resources and job demands. Work and Occupations, 39(1), 7198.

Gilmour, A., Thompson, R., \& Cullis, B. (1995). Average information REML: An efficient algorithm for variance parameter estimation in linear mixed models. Biometrics, 51(4), 1440-1450.

Goldberg, D., \& Hillier, V. (1979). A scaled version of the General Health Questionnaire. Psychological Medicine, 9(1), 139-145.

Golden, T. (2012). Altering the effects of work and family conflict on exhaustion: Telework during traditional and nontraditional work hours. Journal of Business and Psychology, 27(3), 255-269.

Golden, T., Veiga, J., \& Simsek, Z. (2006). Telecommuting's differential impact on workfamily conflict: Is there no place like home? Journal of Applied Psychology, 91(6), 13401350.

Golden, T., Veiga, J. , \& Dino, R. (2008). The impact of professional isolation on teleworker job performance and turnover intentions: Does time spent teleworking, interacting face-toface, or having access to communication-enhancing technology matter? Journal of Applied Psychology, 93(6), 1412-121.

Grawitch, M., Gottschalk, M., \& Munz, D. (2006). The path to a healthy workplace: A critical review linking healthy workplace practices, employee well-being, and organizational improvements. Consulting Psychology Journal: Practice and Research, 58(3), 129-146.

Greenhaus, J., \& Beutell, N. (1985). Sources of conflict between work and family roles. Academy of Management Review, 10(1), 76-88.

Greenhaus, J., \& Powell, G. (2003). When work and family collide: Deciding between competing role demands. Organizational Behavior and Human Decision Processes, 90(2), 291-303.

Greer, T., \& Payne, S. (2014). Overcoming telework challenges: Outcomes of successful telework strategies. The Psychologist-Manager Journal, 17(2), 87-111.

Groen, B., van Triest, S., Coers, M., \& Wtenweerde, N. (2018). Managing flexible work arrangements: Teleworking and output controls. European Management Journal, 36(6), 727-735.

Hammer, L., Kossek, E., Anger, W., Bodner, T., \& Zimmerman, K. (2011). Clarifying workfamily intervention processes: The roles of work-family conflict and family-supportive supervisor behaviors. Journal of Applied Psychology, 96(1), 134-150.

Hammer, L., Demsky, C., Kossek, E., \& Bray, J. (2016). Work-family intervention research. In T. Allen \& L. Eby (Eds.), The Oxford handbook of work and family (pp. 349-361). New York, NY, US: Oxford University Press.

Harker Martin, B., \& MacDonnell, R. (2012). Is telework effective for organizations? A metaanalysis of empirical research on perceptions of telework and organizational outcomes. Management Research Review, 35(7), 602-616. 
Hill, E., Ferris, M., \& Märtinson, V. (2003). Does it matter where you work? A comparison of how three work venues (traditional office, virtual office, and home office) influence aspects of work and personal/family life. Journal of Vocational Behavior, 63(2), 220-241.

Hill, E., Miller, B., Weiner, S., \& Colihan, J. (1998). Influences of the virtual office on aspects of work and work/life balance. Personnel Psychology, 51(3), 667-683.

Huang, J. (2012). Be proactive as empowered? The role of trust in one's supervisor in psychological empowerment, feedback seeking, and job performance. Journal of Applied Social Psychology, 42, E103-E127.

Kalliath, T., \& Brough, P. (2008). Work-life balance: A review of the meaning of the balance construct. Journal of Management \& Organization, 14(3), 323-327.

Kelly, E., Kossek, E., Hammer, L., Durham, M., Bray, J., Chermack, K., ... \& Kaskubar, D. (2008). Getting there from here: Research on the effects of work-family initiatives on workfamily conflict and business outcomes. Academy of Management Annals, 2(1), 305-349.

Kossek, E., Hammer, L., Kelly, E., \& Moen, P. (2014). Designing work, family \& health organizational change initiatives. Organizational Dynamics, 43(1), 53-63.

Kossek, E., Lautsch, B., \& Eaton, S. (2006). Telecommuting, control, and boundary management: Correlates of policy use and practice, job control, and work-family effectiveness. Journal of Vocational Behavior, 68(2), 347-367.

Kossek, E., Lewis, S., \& Hammer, L. (2010). Work-life initiatives and organizational change: Overcoming mixed messages to move from the margin to the mainstream. Human Relations, 63(1), 3-19.

Kossek, E., Hammer, L., Kelly, E., \& Moen, P. (2014). Designing work, family \& health organizational change initiatives. Organizational Dynamics, 43, 53-63

Kooij, D., Guest, D., Clinton, M., Knight, T., Jansen, P., \& Dikkers, J. (2013). How the impact of HR practices on employee well-being and performance changes with age. Human Resource Management Journal, 23(1), 18-35.

Kröll, C., Doebler, P., \& Nüesch, S. (2017). Meta-analytic evidence of the effectiveness of stress management at work. European Journal of Work and Organizational Psychology, 26(5), 677-693.

Kühnel, J., Sonnentag, S., \& Bledow, R. (2012). Resources and time pressure as day-level antecedents of work engagement. Journal of Occupational and Organizational Psychology, 85(1), 181-198.

Lakens, D. (2013). Calculating and reporting effect sizes to facilitate cumulative science: a practical primer for t-tests and ANOVAs. Frontiers in Psychology, 4, article 863.

Lamond, D., Standen, P., \& Daniels, K. (1998). Contexts, cultures and forms of teleworking. In G. Griffin (Ed.), Management theory and practice: Moving to a new era (pp. 145-157).

Lee, S., \& Hong, J. (2011). Does family-friendly policy matter? Testing its impact on turnover and performance. Public Administration Review, 71(6), 870-879.

Lembrechts, L., Zanoni, P., \& Verbruggen, M. (2016). The impact of team characteristics on the supervisor's attitude towards telework: A mixed-method study. The International Journal of Human Resource Management, 1-29. 
Levine, T., \& Hullett, C. (2002). Eta squared, partial eta squared, and misreporting of effect size in communication research. Human Communication Research, 28(4), 612-625.

Mann, S., \& Holdsworth, L. (2003). The psychological impact of teleworking: Stress, emotions and health. New Technology, Work and Employment, 18(3), 196-211.

Major, V., Klein, K., \& Ehrhart, M. (2002). Work time, work interference with family, and psychological distress. Journal of applied psychology, 87(3), 427-436.

Marshall, N., Barnett, R., \& Sayer, A. (1997). The changing workforce, job stress, and psychological distress. Journal of Occupational Health Psychology, 2(2), 99-107.

Melchior, M., Caspi, A., Milne, B., Danese, A., Poulton, R., \& Moffitt, T. (2007). Work stress precipitates depression and anxiety in young, working women and men. Psychological Medicine, 37(8), 1119-1129.

Mesmer-Magnus, J., \& Viswesvaran, C. (2006). How family-friendly work environments affect work/family conflict: A meta-analytic examination. Journal of Labor Research, 27(4), 555574.

Miles, J. \& Shevlin, M. (2001). Applying regression and correlation: A guide for students and researchers. Sage: London.

Moen, P., Kelly, E. L., Tranby, E., \& Huang, Q. (2011). Changing work, changing health: can real work-time flexibility promote health behaviors and well-being? Journal of Health and Social Behavior, 52(4), 404-429.

Morganson, V., Major, D., Oborn, K., Verive, J., \& Heelan, M. (2010). Comparing telework locations and traditional work arrangements: Differences in work-life balance support, job satisfaction, and inclusion. Journal of Managerial Psychology, 25(6), 578-595.

Nayani, R., Nielsen, K., Daniels, K., Donaldson-Feilder, E., \& Lewis, R. (2018). Out of sight and out of mind? A literature review of occupational safety and health leadership and management of distributed workers. Work \& Stress, 32(2), 124-146.

Nielsen, K., \& Miraglia, M. (2017). What works for whom in which circumstances? On the need to move beyond the 'what works?' question in organizational intervention research. Human Relations, 70(1), 40-62.

Olejnik, S., \& Algina, J. (2003). Generalized eta and omega squared statistics: measures of effect size for some common research designs. Psychological Methods, 8(4), 434-47.

Olson-Buchanan, J., \& Boswell, W. (2006). Blurring boundaries: Correlates of integration and segmentation between work and nonwork. Journal of Vocational behavior, 68(3), 432-445.

O'Driscoll, M., Poelmans, S., Spector, P., Kalliath, T., Allen, T., Cooper, C., \& Sanchez, J. (2003). Family-responsive interventions, perceived organizational and supervisor support, work-family conflict, and psychological strain. International Journal of Stress Management, 10(4), 326-344.

Parent-Thirion, A., Biletta, I., Cabrita, J., Vargas, Llave, O., Vermeylen, G., Wilczyńska, A., \& Wilkens, M. (2016). Sixth European Working Conditions Survey.

Petrou, P., Demerouti, E., Peeters, M., Schaufeli, W., \& Hetland, J. (2012). Crafting a job on a daily basis: Contextual correlates and the link to work engagement. Journal of Organizational Behavior, 33(8), 1120-1141. 
Poelmans, S., \& Beham, B. (2008). The moment of truth: Conceptualizing managerial worklife policy allowance decisions. Journal of Occupational and Organizational Psychology, 81(3), 393-410. https://doi.org/10.1348/096317908X314865

Poelmans, S., \& Stepanova, E. (2016). A neuroscience perspective of the work-family-life interface. In T. Allen \& L. Eby (Eds.), The Oxford handbook of work and family (pp. 401416). New York: Oxford University Press.

Randstad (2017). Randstad Employer Brand Research 2017 global report. Available online at: https://cdn2.hubspot.net/hubfs/481927/Campaigns/REBR\%202017/Randstad\%20Employe r\%20Brand\%20Research\%202017\%20-\%20global\%20report.pdf (accessed 21 August 2018)

Revelle, W., \& Joshua, W. (2019). Analyzing dynamic data: A tutorial. Personality and Individual Differences, 136, 38-51.

Richman, A., Civian, J., Shannon, L., Hill, J., \& Brennan, R. (2008). The relationship of perceived flexibility, supportive work-life policies, and use of formal flexible arrangements and occasional flexibility to employee engagement and expected retention. Community, Work and Family, 11(2), 183-197.

Rivkin, W., Diestel, S., \& Schmidt, K. (2016). Which daily experiences can foster well-being at work? A diary study on the interplay between flow experiences, affective commitment, and self-control demands. Journal of Occupational Health Psychology, 23(1), 99-111.

Shadish, W., \& Cook, T. (2009). The renaissance of field experimentation in evaluating interventions. Annual Review of Psychology, 60, 607-629.

Sonnentag, S., Dormann, C., \& Demerouti, E. (2010). Not all days are created equal: The concept of state work engagement, in A. Bakker \& M. Leiter, Work engagement: A handbook of essential theory and research (pp. 25-38).

Thomas, G., Zolin, R., \& Hartman, J. (2009). The central role of communication in developing trust and its effect on employee involvement. The Journal of Business Communication, 46(3), 287-310.

Thompson, C., \& Prottas, D. (2006). Relationships among organizational family support, job autonomy, perceived control, and employee well-being. Journal of Occupational Health Psychology, 11(1), 100-118.

Madsen, S. (2003). The effects of home-based teleworking on work-family conflict. Human Resource Development Quarterly, 14(1), 35-58.

Mann, S., \& Holdsworth, L. (2003). The psychological impact of teleworking: Stress, emotions and health. New Technology, Work and Employment, 18(3), 196-211.

Sardeshmukh, S., Sharma, D., \& Golden, T. (2012). Impact of telework on exhaustion and job engagement: A job demands and job resources model. New Technology, Work and Employment, 27(3), 193-207.

Schaufeli, W., Bakker, A., \& Salanova, M. (2006). The measurement of work engagement with a short questionnaire: A cross-national study. Educational and Psychological Measurement, 66(4), 701-716.

Schieman, S., \& Young, M. (2010). Is there a downside to schedule control for the work-family 
interface? Journal of Family Issues 31(10), 1391-1314.

Shrout, P., \& Lane, S. (2012). Psychometrics. In M. Mehl \& T. Conner (Eds.), Handbook of research methods for studying daily life (p. 302-320). The Guilford Press.

Smit, B., Maloney, P., Maertz, C., \& Montag-Smit, T. (2016). Out of sight, out of mind? How and when cognitive role transition episodes influence employee performance. Human Relations, 69(11), 2141-2168.

Sonnentag, S. (2017). A task-level perspective on work engagement: A new approach that helps to differentiate the concepts of engagement and burnout. Burnout Research, 5, 12-20.

Standen, P., Daniels, K., \& Lamond, D. (1999). The home as a workplace: Work-family interaction and psychological well-being in telework. Journal of Occupational Health Psychology, 4(4), 368-381.

Stephens, G., \& Szajna, B. (1998). Perceptions and expectations: Why people choose a telecommuting work style. International Journal of Electronic Commerce, 3(1), 70-85.

Sullivan, C. (2003). What's in a name? Definitions and conceptualisations of teleworking and homeworking. New Technology, Work and Employment, 18(3), 158-165.

Thompson, C., Beauvais, L., \& Lyness, K. (1999). When work-family benefits are not enough: The influence of work-family culture on benefit utilization, organizational attachment, and work-family conflict. Journal of Vocational Behavior, 54(3), 392-415.

Towers, I., Duxbury, L., Higgins, C., \& Thomas, J. (2006). Time thieves and space invaders: Technology, work and the organization. Journal of Organizational Change Management, 19(5), 593-618.

Vega, R., Anderson, A., \& Kaplan, S. (2015). A within-person examination of the effects of telework. Journal of Business and Psychology, 30(2), 313-323.

Weiss, H., \& Cropanzano, R. (1996). Affective events theory: A theoretical discussion of the structure, causes and consequences of affective experiences at work. In B. Staw \& L. Cummings (Eds.), Research in organizational behavior: An annual series of analytical essays and critical reviews, Vol. 18 (pp. 1-74). US: Elsevier Science/JAI Press.

Westman, M., \& Piotrkowski, C. (1999). Introduction to the special issue: Work-family research in occupational health psychology. Journal of Occupational Health Psychology, 4(4), 301-306.

Wilson, M., Dejoy, D., Vandenberg, R., Richardson, H., \& McGrath, A. (2004). Work characteristics and employee health and well-being: Test of a model of healthy work organization. Journal of Occupational and Organizational Psychology, 77(4), 565-588.

Windeler, J., Chudoba, K., \& Sundrup, R. (2017). Getting away from them all: Managing exhaustion from social interaction with telework. Journal of Organizational Behavior, 38(7), 977-995.

Wood, S. (2011). Fast stable restricted maximum likelihood and marginal likelihood estimation of semiparametric generalized linear models. Journal of the Royal Statistical Society: Series B (Statistical Methodology), 73(1), 3-36.

Wright, T., \& Cropanzano, R. (2000). Psychological well-being and job satisfaction as predictors of job performance. Journal of Occupational Health Psychology, 5(1), 84-94. 
Xanthopoulou, D., Bakker, A., Demerouti, E., \& Schaufeli, W. (2009). Work engagement and financial returns: A diary study on the role of job and personal resources. Journal of Occupational and Organizational Psychology, 82(1), 183-200. 


\section{Tables}

Table 1. Means, standard deviations and correlations for trait variables in the pretest-posttest analyses

\begin{tabular}{|c|c|c|c|c|c|c|c|c|c|c|c|c|}
\hline Variable & $M$ & $S D_{B}$ & 1 & 2 & 3 & 4 & 5 & 6 & 7 & 8 & 9 & 10 \\
\hline \multicolumn{13}{|c|}{ 1. Group $(1=$ intervention $) \mathrm{T} 1$} \\
\hline 2. Stress T1 & 3.23 & 1.10 & -0.09 & & & & & & & & & \\
\hline 3. WHC, time-based T1 & 4.63 & 1.57 & 0.07 & $0.43 * *$ & & & & & & & & \\
\hline 4. WHC, strain-based T1 & 3.97 & 1.44 & 0.02 & $0.57 * *$ & $0.54 * *$ & & & & & & & \\
\hline 5. Work engagement T1 & 5.17 & 0.95 & 0.18 & $-0.36 * *$ & -0.07 & -0.07 & & & & & & \\
\hline 6. Job performance $\mathrm{T} 1$ & 5.48 & 0.75 & $0.28 * *$ & $-0.26^{*}$ & 0.07 & -0.01 & $0.64 * *$ & & & & & \\
\hline 7. Stress $\mathrm{T} 2$ & 2.88 & 1.17 & -0.24 & $0.75^{* *}$ & 0.23 & $0.43 * *$ & $-0.36 * *$ & $-0.30 *$ & & & & \\
\hline 8. WHC, time-based T2 & 4.24 & 1.74 & 0.01 & $0.32 *$ & $0.73 * *$ & $0.38 * *$ & -0.12 & 0.22 & $0.26^{*}$ & & & \\
\hline 9. WHC, strain-based T2 & 3.45 & 1.61 & -0.08 & $0.38 * *$ & $0.40 * *$ & $0.65 * *$ & -0.13 & 0.09 & $0.45^{* *}$ & $0.58 * *$ & & \\
\hline 10. Work engagement $\mathrm{T} 2$ & 5.00 & 1.01 & 0.24 & $-0.46^{* *}$ & -0.15 & -0.21 & $0.76^{* *}$ & $0.51 * *$ & $-0.52 * *$ & -0.10 & -0.22 & \\
\hline 11. Job performance $\mathrm{T} 2$ & 5.50 & 0.75 & 0.23 & $-0.30 *$ & 0.00 & -0.00 & $0.54 * *$ & $0.53 * *$ & $-0.44 * *$ & 0.07 & -0.01 & $0.72 * *$ \\
\hline
\end{tabular}
${ }^{* *} p<0.01,{ }^{*} p<0.05 . N_{\mathrm{T} 1}=78, N_{\mathrm{T} 2}=65 . W H C=$ Work-to-home conflict. $M=$ Mean. $S D_{B}=$ Between-person standard deviation. Means are on a 1-7 Likert scale. 
Table 2. Means, standard deviations, and results of repeated measures analyses of variance (MANOVAs) - without control variables - for study variables at pretest (T1) and posttest (T2) measurement occasion comparing intervention and control group of the employees who filled in both $\mathrm{T} 1$ and $\mathrm{T} 2$ in the teleworking group and the control group

\begin{tabular}{lcccccc|cc}
\hline & \multicolumn{3}{c}{ Teleworking group $^{\mathrm{a}}$} & \multicolumn{3}{c|}{ Control group $^{\mathrm{b}}$} & \multicolumn{2}{c}{ MANOVA $^{\mathrm{c}}$} \\
\hline & $\mathrm{T} 1$ & $\mathrm{~T} 1$ & $\Delta(\mathrm{T} 2-\mathrm{T} 1)$ & $\mathrm{T} 1$ & $\mathrm{~T} 2$ & $\Delta(\mathrm{T} 2-\mathrm{T} 1)$ & $\eta_{\mathrm{p}}{ }^{2}$ & power $^{2}$ \\
\hline Stress & $3.08(0.95)$ & $2.62(1.04)$ & $-0.46(0.84)$ & $3.24(1.23)$ & $3.18(1.27)$ & $-0.06(0.73)$ & $0.06^{*}$ & 0.52 \\
WHC, time-based & $4.73(1.33)$ & $4.26(1.75)$ & $-0.46(1.25)$ & $4.52(1.68)$ & $4.22(1.78)$ & $-0.30(1.21)$ & 0.00 & 0.08 \\
WHC, strain-based & $3.95(1.26)$ & $3.31(1.61)$ & $-0.64(1.42)$ & $3.99(1.58)$ & $3.58(1.65)$ & $-0.41(1.11)$ & 0.01 & 0.11 \\
Work engagement & $5.29(0.96)$ & $5.22(0.96)$ & $-0.07(0.50)$ & $4.93(0.93)$ & $4.75(1.05)$ & $-0.18(0.86)$ & 0.01 & 0.10 \\
Job performance & $5.68(0.70)$ & $5.66(0.66)$ & $-0.02(0.52)$ & $5.22(0.70)$ & $5.32(0.82)$ & $0.10(0.91)$ & 0.01 & 0.09 \\
\hline
\end{tabular}

${ }^{\mathrm{a}} \mathrm{n}=34 .{ }^{\mathrm{b}} \mathrm{n}=30 .{ }^{\mathrm{c}} \eta_{\mathrm{p}}{ }^{2}=$ partial eta squared effects sizes and the respective power of the interaction of time (i.e. T1, T2) with group

(i.e. teleworking group, control group) on the specific outcome. 
Table 3. Means, standard deviations and correlations for state variables in the daily analyses

\begin{tabular}{lccccccccc}
\hline Variable & $M$ & $S D_{B}$ & $S D_{W}$ & 1 & 2 & 3 & 4 & 5 & 6 \\
\hline 1. Teleworking day & 0.12 & 0.18 & 0.30 & & $-0.28^{* *}$ & $-0.16^{* *}$ & $-0.18^{* *}$ & $0.22^{* *}$ & $0.21^{* *}$ \\
2. Daily stress & 2.67 & 0.88 & 0.76 & -0.08 & & $0.30^{* *}$ & 0.45 & -0.44 & $-0.23^{* *}$ \\
3. Daily WHC (time) & 2.74 & 1.34 & 1.52 & 0.13 & 0.20 & & $0.62^{* *}$ & -0.05 & -0.01 \\
4. Daily WHC (strain) & 2.41 & 1.29 & 1.17 & 0.22 & $0.53^{* *}$ & $0.71^{* *}$ & & $-0.21^{* *}$ & -0.06 \\
5. Daily work engagement & 4.70 & 0.90 & 0.76 & 0.08 & $-0.59^{* *}$ & 0.12 & -0.13 & & $0.56^{* *}$ \\
6. Daily job performance & 5.24 & 1.23 & 1.22 & -0.02 & $-0.56^{* *}$ & 0.19 & -0.01 & $0.78^{* *}$ & \\
\hline
\end{tabular}

$* * p<0.01, * p<0.05 . N=77$ persons (1 person did not fill in any of the daily surveys) and $N=741$ occasions. $M=$ Mean. $S D_{B}=$ Between-person standard deviation. $S D_{W}=$ Within-person standard deviation. Means are on a 1-7 Likert scale. Within-person correlations are shown above and between-person correlations are shown below the diagonal. Between-person correlations, means and standard deviations are person-mean centered (i.e. based on averaged scores across all measurement occasions per person), except for teleworking day. 
Table 4. Random coefficient modeling results to predict stress (Model 1), time-based work-tohome conflict (Model 2), strain-based work-to-home conflict (Model 3), work engagement (Model 4) and job performance (Model 5).

\begin{tabular}{|c|c|c|c|c|c|c|c|c|c|c|}
\hline & \multirow{2}{*}{\multicolumn{2}{|c|}{$\begin{array}{c}\text { Model } 1 \\
\text { Stress }\end{array}$}} & \multirow{2}{*}{\multicolumn{2}{|c|}{$\frac{\text { Model } 2}{\text { WHC (time) }}$}} & \multirow{2}{*}{\multicolumn{2}{|c|}{$\frac{\text { Model } 3}{\text { WHC (strain) }}$}} & \multirow{2}{*}{\multicolumn{2}{|c|}{$\begin{array}{c}\text { Model } 4 \\
\text { Work engagement }\end{array}$}} & \multicolumn{2}{|c|}{ Model 5} \\
\hline & & & & & & & & & \multicolumn{2}{|c|}{ Job performance } \\
\hline & $\gamma$ & SE & $\gamma$ & SE & $\gamma$ & SE & $\gamma$ & SE & $\gamma$ & SE \\
\hline Intercept & $.04 * * *$ & .09 & $.08 * * *$ & .09 & $.07^{* * * *}$ & .10 & $.01 * * *$ & .10 & $.03 * * *$ & 0.08 \\
\hline Teleworking day $(1=$ yes $)$ & $-.20 * * *$ & .03 & $-.12 * * *$ & .03 & $-.12^{* * *}$ & .03 & $.14 * * *$ & .03 & $.18 * * *$ & 0.11 \\
\hline Group (1 = intervention) & .03 & .09 & .06 & .09 & .09 & .10 & .12 & .10 & -.04 & 0.16 \\
\hline Likelihood ratio & \multicolumn{2}{|c|}{$49.88^{* *}$} & \multicolumn{2}{|c|}{$12.45^{* *}$} & \multicolumn{2}{|c|}{$12.78^{* *}$} & \multicolumn{2}{|c|}{$30.46 * *$} & \multicolumn{2}{|c|}{$28.10 * *$} \\
\hline Variance level 2 (person) & \multicolumn{2}{|c|}{$0.77(57 \%)$} & \multicolumn{2}{|c|}{$1.80(56 \%)$} & \multicolumn{2}{|c|}{$1.66(45 \%)$} & \multicolumn{2}{|c|}{$0.82(58 \%)$} & \multicolumn{2}{|c|}{$1.52(57 \%)$} \\
\hline Variance level 1 (day) & \multicolumn{2}{|c|}{$0.57(43 \%)$} & \multicolumn{2}{|c|}{$2.32(44 \%)$} & \multicolumn{2}{|c|}{$1.38(55 \%)$} & \multicolumn{2}{|c|}{$0.58(42 \%)$} & \multicolumn{2}{|c|}{$1.48(49 \%)$} \\
\hline
\end{tabular}

**p $<.001 . \gamma=$ standardized coefficient. $\mathrm{SE}=$ standard error. Likelihood ratio is given for the model comparison with the null model. 